\title{
Adapting Plastic Surgery Residency Training During COVID-19: The Experience of a Chilean University Hospital
}

\author{
Alfonso Navia ${ }^{1}$ Rodrigo Tejos ${ }^{1} \cdot$ Gonzalo Yañez $^{1} \cdot$ Claudio Guerra $^{1} \cdot$ \\ Alvaro Cuadra $^{1} \cdot$ Susana Searle $^{1}$
}

Received: 29 September 2020/Accepted: 4 October 2020/Published online: 15 October 2020

(C) Springer Science+Business Media, LLC, part of Springer Nature and International Society of Aesthetic Plastic Surgery 2020

Keywords Plastic surgery · Training $\cdot$ Resident .

Residency $\cdot$ COVID-19 $\cdot$ Pandemic

Level of Evidence $V$. This journal requires that authors assign a level of evidence to each article. For a full description of these Evidence-Based Medicine ratings, please refer to the Table of Contents or the online Instructions to Authors www.springer.com/00266.

\section{Dear Sir,}

The COVID-19 pandemic not only has affected the activity of health systems but also the routine of postgraduate medical education [1]. While most non-surgical specialties have experienced an increase in demand, surgical specialties have shown a significant decline in their activity, concentrating mainly on emergency surgeries. In the case of plastic surgery residency (PSR), it presents an additional challenge since most of the surgical activity is elective [2]. For this reason, the PSR has had to design strategies to face the pandemic's challenging changes. Previously, some authors have published the experience of their plastic surgery services to face this pandemic. Most of these studies have focused on the organizational structure, use of personal protection elements and safety of medical

Electronic supplementary material The online version of this article (https://doi.org/10.1007/s00266-020-02005-5) contains supplementary material, which is available to authorized users.

Susana Searle

Plasticsurgeryuc2@gmail.com

1 Section of Plastic and Reconstructive Surgery, Surgery Division, School of Medicine, Pontificia Universidad Católica de Chile, Diagonal Paraguay 362, 8330077 Santiago, Chile personnel contact with patients [3]. However, there is limited description of concrete measures to maintain resident education. Zingaretti et al. [2] surveyed Italian plastic surgery residents, with $90 \%$ of them agreeing that the significant decrease in surgical activity would impact their professional growth, proposing didactical virtual reality simulators to maintain anatomical and surgical training. Sliewah et al. [4] published their experience on the use of virtual education for residents, where they highlight the advantages and benefits of using virtual platforms and webinars.

The PSR of the Pontificia Universidad Catolica de Chile (PUC) lasts 3-4 years, depending on the choice to opt for an additional first year of non-clinical research with a master's in science degree. We currently have 7 residents: 1 resident in the preclinical year, 2 first-year residents, 3 second-year residents and 1 third-year resident. The average number of monthly surgeries in a year without a pandemic is 50 cases. After COVID-19, this number has decreased to less than 10 , negatively impacting residents' training due to lack of case exposure. While other plastic surgery services have suffered from staff and resident redeployment-or even residency temporary suspension due to such a low surgical caseload - the plastic surgery team of the PUC, together with its medical education department, designed a teaching strategy to deal with these challenges.

The first strategy was to reorganize the working team, consisting of one resident and one staff plastic surgeon who run a one-week shift followed by a two- or three-week quarantine at home. During this period, they cover urgent reconstructive surgeries cases of cancer or trauma and the important increase in pressure sores consultations due to 
the large number of COVID-19 ventilated patients in critical care units.

Second, concerning education, we are organizing weekly Zoom webinars between our team's residents and staff members in different reconstructive and aesthetic surgery topics where an external national or international plastic surgeon is invited as a speaker to share and discuss their experience (Supplementary Fig. 1). In addition, all trainees participate in the Chilean Plastic Surgery Residents Journal Club and meetings of The Chilean Plastic Surgery Society held once a month by Zoom. In addition, thanks to platforms like FILACP and ICOPLAST Trainees we have been able to be in contact with residents worldwide, sharing and taking advantage of high-quality educational material on an immense variety of topics [5]. Furthermore, plastic surgery residents were encouraged to develop research projects during time off at home, scheduling virtual research meetings twice a month with the rest of the team's senior staff to maintain the work pace, discuss the projects and keep everyone up to date.

Third, regarding training, weekly cadaveric dissection sessions were arranged in our anatomy laboratory, giving residents the opportunity to train surgical techniques supervised by experienced plastic surgeons while using appropriate personal protection equipment and limiting social interaction (Fig. 1). Also, in order to keep microsurgical skills training regularity, each resident was handed a portable microsurgery kit developed and validated by our team (which is in process of publication), enabling safe and comfortable practice at home without the need to attend to our simulation center, allowing even photographic and video distance feedback from experts (Fig. 2). Finally, the Postgraduate Direction of the PUC settled mindfulness

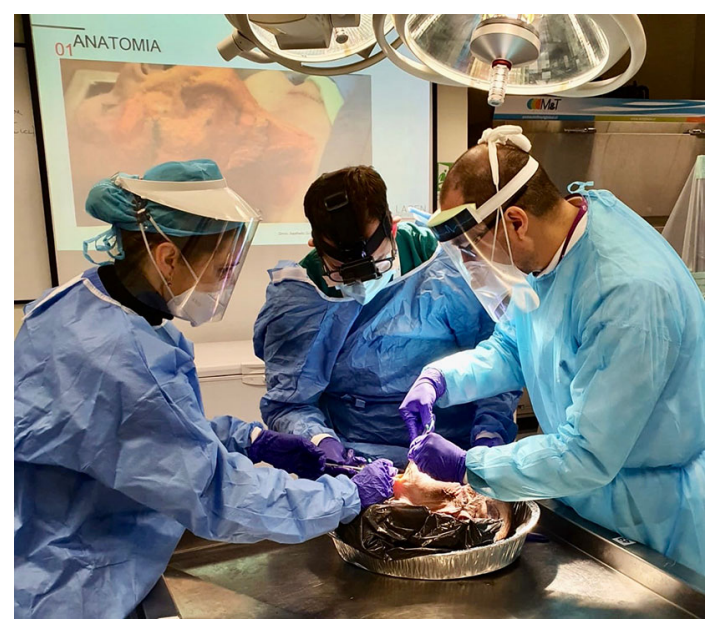

Fig. 1 Weekly cadaveric dissection sessions with adequate personal protective equipment and a maximum of three surgeons/residents per cadaver

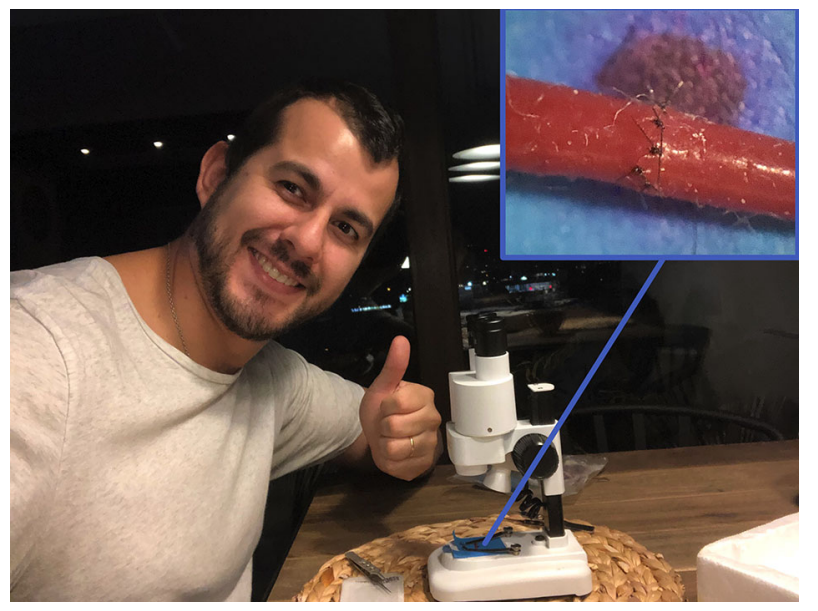

Fig. 2 Resident training microsurgery at home with the portable kit validated by our team

sessions once a week for all of the residents in order to care for their mental health during the pandemic.

No doubt these are challenging times for everyone worldwide, and plastic surgery training has not been the exception. In these highly stressful moments, standard training has changed dramatically forcing us to reformulate traditional means of surgical education. Technologies like the Internet and advances in training like remote simulation, webinars and cadaveric sessions have provided us a new strategy to continue education in PSR. Also, other measures like national reconstructive surgical missions could help us complement the surgical caseload by concentrating cases in regions that lack plastic surgeons, but only once the pandemic and social distancing measures start to ease. Probably, these difficult times in which we are living could make traditional face-to-face education evolve, implementing virtual and distant-based education as part of core training plastic surgery residency programs.

Acknowledgements The authors would like to thank Doctors Teresa de la Cerda, Natacha Quezada, Linda Rincón, Caroll May, Diego Marré, Jose Lasen, Kenneth Guler, Robert Grant and Marco Romeo for their contributions to our resident's training during the pandemic.

Funding The authors received no financial support for the research, authorship and publication of this article.

\section{Compliance with Ethical Standards}

Conflict of interest The authors declare that they have no conflict of interest to disclose.

Ethical Approval This article does not contain any studies with human participants or animals performed by any of the authors.

Informed Consent For this type of study, informed consent is not required. 


\section{References}

1. Potts JR 3rd (2020) Residency and fellowship program accreditation: effects of the novel coronavirus (COVID-19) pandemic. J Am Coll Surg 230:1094-1097

2. Zingaretti N, Contessi Negrini F, Tel A et al (2020) The impact of COVID-19 on plastic surgery residency training. Aesthet Plast Surg. https://doi.org/10.1007/s00266-020-01789-w

3. Armstrong A, Jeevaratnam J, Murphy G et al (2020) A plastic surgery service response to COVID-19 in one of the largest teaching hospitals in Europe. J Plast Reconstr Aesthet Surg 73:1174-1205
4. Sleiwah A, Mughal M, Hachach-Haram N, Roblin P (2020) COVID-19 lockdown learning: the uprising of virtual teaching. J Plast Reconstr Aesthet Surg. https://doi.org/10.1016/j.bjps.2020. 05.032

5. Navia A, Berner JE, Pereira N et al (2020) Have we passed the peak The COVID-19 plastic surgery webinar pandemic. Aesthet Surg J 40(9):569-573

Publisher's Note Springer Nature remains neutral with regard to jurisdictional claims in published maps and institutional affiliations. 